Rev. Adm. Saúde - Vol. 18, № 72, jul. - set. 2018

http://dx.doi.org/10.23973/ras.72.119

RELATO DE CASO

\title{
Implementação de um modelo de gestão de serviços de saúde ocupacional em uma indústria metalúrgica do vale do paraíba SP
}

Occupational health care management model implementation in a metallurgical industry located at Vale do Paraiba SP

\section{Renato Ribeiro Nogueira Ferraz¹, Gunther Monteiro de Paula Guirado²}

1. Biólogo, pós-doutor em ciências básicas. Mestrando em gestão de sistemas de saúde da Universidade Nove de Julho (UNINOVE), São Paulo SP

2. Médico, especialista em medicina do trabalho. Afiliado a Universidade de Taubaté (UNITAU), Taubaté SP

\section{RESUMO}

Este relato de experiência visa descrever a implantação de um modelo de gestão operacional no serviço de saúde ocupacional de uma empresa metalúrgica localizada no Vale do Paraíba - SP, no período entre outubro de 2014 e junho de 2016. Para tal, foi realizada análise documental do serviço e das demais áreas correlatas, envolvendo desdobramentos dos processos internos que norteavam a gestão em saúde na empresa. Após a análise, foram introduzidas na empresa diversas ferramentas de gestão, como o plano estratégico situacional, a cultura organizacional, as abordagens clássica e contemporânea da administração, dentre outros. Com as mudanças, foi possível organizar a operacionalização do serviço de saúde da empresa, certificando-se que as questões socioculturais locais, além dos aspectos emocionais dos envolvidos na equipe de saúde ocupacional, fossem respeitados.

Palavras-chave: gestão em saúde, saúde do trabalhador, medicina do trabalho. 


\begin{abstract}
This experience report aims to describe the operational management model implementation in occupational health service of a metallurgical company located in Vale do Paraiba - SP, between October 2014 and June 2016. For this purpose, a documentary analysis of Service and other related areas was conducted, involving unfolding of internal processes that guided company health management. After the analysis, many management tools were started, such as Situational Strategic Plan, Organizational Culture, Classical and Contemporary Approaches of Management, among others. With the changes, it was possible to organize the operation of company health service, making sure that the local sociocultural issues, besides the emotional aspects of those involved in the occupational health team, were respected.
\end{abstract}

Keywords: health management, occupational health, occupational medicine.

\title{
INTRODUÇÃO
}

A globalização é uma característica bastante comum nas principais economias mundiais, envolvendo o desenvolvimento de novas tecnologias voltadas a suprir a emergência das expectativas individuais. As mudanças nos aspectos sociais exigem das empresas novas formas de ação, além de grandes avanços na capacidade competitiva. Nesse sentido, a saúde do trabalhador passa a apresentar forte impacto na produtividade, tornando-se um diferencial no posicionamento do capital humano da empresa, e refletindo diretamente no desempenho em seu ramo de atividade específico (1).

Com a evolução das empresas, a gestão operacional dos serviços de saúde ocupacional também deve acompanhar estas mudanças, com resiliência e observação aos acontecimentos que norteiam cada ramo de atividade econômica, aprimorando o serviço de saúde neste contexto. Sob este prisma, as empresas devem estar conectadas não apenas à questão da saúde dos funcionários locais, mas também devem se manter atentas aos acontecimentos internacionais, nacionais e regionais relacionados ao ramo de atividade econômica de cada organização. Neste passo, uma gestão sustentada, contínua e eficiente, com bons resultados, dependerá de um gestor com objetivos claros e com estreita relação entre a abordagem teórico-metodológica e a prática diária (2).

Na contextualização da gestão de saúde no interior das empresas, inicialmente cabe ressaltar os critérios estabelecidos pela Occupational Health and Safety 
Assessment Services (OHSAS), no caso específico a OHSAS 18001, que traz em seu bojo as políticas de saúde e segurança ocupacional das organizações mundiais, explorando a natureza de suas atividades, e as condições sob as quais operam. Ressalta-se a importância de compartilhar estas ações entre as organizações, em conjunto com a ISO 9001 (sistema de gestão da qualidade), e ISO 14001 (gestão ambiental), preservando ainda mais a integridade física de seus colaboradores e parceiros, visto que, cumprindo estes critérios, certamente atenderão as exigências da legislação nacional $(3,4)$.

Por intermédio da OHSAS 18001, as empresas terão um referencial que thes permite serem avaliadas e certificadas por uma organização externa, possibilitando melhora contínua de seus procedimentos, e ainda com um diferencial de mercado. Neste âmbito, estudos do ambiente interno se mostram capazes de proporcionar condições para elaboração de políticas mediante os comportamentos que a própria empresa apresenta. Ainda, por meio destes, torna-se possível propor planos de ação, instituir indicadores, metas e auditorias, tudo com critério e abrangência detalhada aos responsáveis pela gestão da saúde (3-5).

Em meio ao mundo globalizado, às dinâmicas empresariais e aos critérios das normas a serem cumpridas na saúde, o gestor precisará ser criterioso e organizado, bem como conhecer ferramentas de Gestão do Conhecimento (GC), a fim de realizar um gerenciamento eficaz e apropriado às características do setor de saúde da empresa local. Daí surge a complexidade também em diferenciar GC da tecnologia da informação (TI). A TI disponibilizará a capacidade de obter a informação certa, no local certo e no menor tempo possível. Entretanto, entende-se que a peça fundamental para o sucesso do processo seja a GC, que transforma o conhecimento pessoal do gestor em conhecimento corporativo, alavancando o aproveitamento dos recursos e experiências do serviço local (6).

Todos os funcionários de um serviço de saúde ocupacional devem possuir a capacidade de selecionar e implementar práticas para gerir o conhecimento, de modo a não repetir no futuro os problemas do passado, e a desenvolver soluções rápidas na vigência de um novo problema. Em suma, o gestor passa a ser responsável por disseminar esta cultura entre os membros de sua equipe de trabalho, implementando na prática a filosofia que busca extrair de cada um o conhecimento que possui, e canalizando as diversas soluções com vistas a minimizar os entraves cotidianos. Sob o aspecto científico, a GC tem chamado cada vez mais a atenção de estudiosos como forma de conduzir melhor os processos de gestão de uma empresa, provendo suporte desde o diagnóstico organizacional até os processos de criação, ou mesmo conservação de métodos tradicionais, os quais desde a década passada já necessitavam de ajustes para prática empresarial (6).

Neste passo, os médicos do trabalho, que atuam como gestores de serviços de medicina ocupacional, precisam de conhecimentos que os permitam implementar estratégias ou modelos de gestão, seja da GC, da TI, ou de competências que respondam às necessidades de cada local, buscando influenciar positivamente no grau de satisfação dos trabalhadores, e consequentemente, gerando resultados positivos para a organização como um 
todo. Dessa forma, a implementação de um modelo de gestão de saúde ocupacional sistematizado, descrevendo estrutura física e modos operacionais, certamente proporcionará aos gestores auxílio nos processos internos das mais distintas organizações.

\section{OBJETIVO}

Descrever a experiência da implementação de um novo modelo de gestão de serviço de saúde ocupacional em uma empresa metalúrgica localizada no Vale do Paraíba, Estado de São Paulo, bem como apresentar os principais resultados oriundos da referida implementação.

\section{MATERIAL E MÉTODOS}

A presente pesquisa se trata de um estudo descritivo, com base em um relato de experiência, que descreve as atividades teórico-práticas gerenciais implementadas em uma empresa do ramo de metalurgia, e relativas à reestruturação física e operacional do seu serviço ocupacional de saúde. As atividades aqui relatadas foram desenvolvidas durante um curso de Master of Business Administration (MBA) em gestão em saúde realizado por um dos autores do presente relato, no período compreendido entre outubro de 2014 e junho de 2016.

De início, foi realizada uma análise documental do serviço de saúde ocupacional e das demais áreas correlatas, as quais envolvem os desdobramentos dos processos internos que norteiam a gestão em saúde na empresa. Os documentos avaliados se encontravam disponíveis em um banco de dados de acesso direto à coordenação de saúde da empresa, assim como para suas áreas correlatas. Após os inventários, seguiu-se a abordagem operacional com os trabalhadores.

No que se refere à estrutura operacional, foram observados diversos documentos relacionados aos aspectos inerentes à gestão em saúde. Nesta etapa, a medida que foram sendo relatadas as diversas situações problema, foi possível introduzir uma série de ferramentas, tais como:

- o plano estratégico situacional,

- a cultura organizacional,

- as abordagens clássica e contemporânea da administração,

- a utilização do conhecimento, a geração de novas práticas,

- a gestão financeira e de custos,

- a gestão de insumos e suprimentos,

- a gestão pela qualidade,

- a tecnologia da informação e comunicação,

- a auditoria em sistema de saúde,

- o empreendedorismo interno e externo,

- as inovações, 
- a gestão de pessoas,

- os sistemas e serviços de saúde,

- o trabalho em equipe interdisciplinar, e

- a tomada de decisão nas organizações.

\section{RESULTADOS}

Primeiramente, no final de setembro de 2012, foi realizada uma varredura de todos os documentos contidos na área de saúde local, buscando em paralelo associar as informações do referido inventário, certificando as exigências de cada aspecto legal, seguindo assim a mesma linha de raciocínio utilizada na reestruturação física e operacional. Nestas fases de curto, médio e longo prazo, atentou-se para os aspectos culturais da empresa, sempre buscando aproximação com as estratégias do negócio, consolidando as mudanças, dessa forma, em conjunto com o meio empresarial, levando em consideração a ideologia, missão, visão e valores da companhia.

Diante da globalização e da formação básica como médico do trabalho de um dos autores do presente estudo, este iniciou, em outubro de 2014, um curso de MBA em gestão em saúde, afim de aprimorar cada etapa da reestruturação com base nos conhecimentos de gestão em saúde adquiridos no referido curso, em consonância com os princípios de saúde ocupacional, processo finalizado no ano de 2016.

Neste passo, ocorreram grandes transformações nas adequações dos documentos internos da empresa (7), sempre interligando e aproximando os setores de recursos humanos, segurança do trabalho e saúde ocupacional. Nesta fase, foram reestruturados os documentos base, além de adequadas as plataformas de Grupos Homogêneos de Exposição (GHE), realinhados os descritivos do Programa de Controle Médico de Saúde Ocupacional (PCMSO), onde também são emitidos os Atestados de Saúde Ocupacional (ASO), sendo este harmonizando com o Programa de Conservação Auditiva (PCA), o Programa de Proteção Respiratória (PPR), e o Programa de Gerenciamento de Resíduos de Serviço de Saúde (PGRSS). Também foram criados o Programa de Educação Postural (PEP), o Programa de Pessoas com Deficiências (PPCD), o Programa de Qualidade de Vida no Trabalho (PQVT), o Programa de Retorno ao Trabalho (PRT).

Partindo de todo arcabouço técnico, e somando-se a isso a vivência das transformações ocorridas no período, foi sendo desenhada ao longo do tempo uma estrutura com foco em atender os funcionários, minimizando o impacto na produtividade da empresa (8), como por exemplo, a informatização da área com a utilização de um software online de gestão ocupacional, adequação de layout da planta local de saúde, e capacitação dos funcionários de modo a obter melhores resultados do próprio capital humano da empresa, com dicas explicativas quanto à utilização de ferramentas de gestão para este ramo de atividade de saúde. 
Ao longo do tempo, desde o início do processo, no ano de 2012, e principalmente a partir de 2014, a equipe de saúde passou por inúmeras transformações, sendo estruturada a princípio com 27 membros (entre funcionários da própria empresa e prestadores de serviços), sendo um médico do trabalho coordenador, que permanecia na empresa por 30 horas semanais (antes com a mesma carga horária, porém sem atuação de gestão integrada), três médicos assistentes do PCMSO, que totalizavam juntos 50 horas semanais buscando atender todos os turnos de trabalho da empresa, para que pudesse ocorrer um atendimento mais homogêneo e equalizado (antes existia apenas um médico assistente, que permanecia apenas durante o período da manhã). Também foi incorporado à equipe o grupo da enfermagem do trabalho, que permanecia 44 horas semanais em horário comercial (antes tudo ficava sob a responsabilidade apenas de um técnico de enfermagem).

No período noturno, implementou-se a enfermagem assistencial, também com 44 horas semanais de trabalho (inexistente antes da reformulação). Quanto às funções da enfermagem, esta passou a incorporar a Anotação de Responsabilidade Técnica (ART), apresentando condições de adequação requeridas pelo Conselho Regional de Enfermagem (COREN). Para tal, permaneciam em atividades supervisionadas quatro técnicos de enfermagem em escalas de plantão (44 horas cada); um fonoaudiólogo ( 15 horas semanais), ambos atuando no PCA e no PPR sob contínuas revisões junto à equipe de segurança do trabalho e à coordenação de saúde (antes existiam apenas fonoaudiólogo com exames e PCA, sem integração às demais áreas, e sem envolvimento no assessoramento nos suportes do PPR); um fisioterapeuta (15 horas semanais), que passou a realizar Avaliações Físico Funcionais (AFF), além de Gerenciar as Doenças Osteomusculares (GDOM), antes sem este escopo de trabalho; um ergonomista integrado à equipe de Environment, Health and Safety (EHS), também atuando 40 horas semanais nas ações de correção em engenharia ergonômica (antes existia apenas um ergonomista 30 horas semanais, somente no setor de saúde); um assistente administrativo (44 horas semanais), com ações de suporte a toda área de saúde ocupacional, todavia focando no monitoramento do orçamento e dos indicadores da área, sob gestão conjunta com a coordenação de saúde (antes o profissional atuava apenas em ações de saúde, como controle de exames, dentre outros); um auxiliar administrativo (44 horas semanais), com ações focadas na recepção, porém, interligando toda equipe de saúde por intermédio do Software de Gestão Ocupacional (SGO), visto que não existia uma interligação de gestão online com os demais membros da equipe; e por fim, um guarda mirim (24 horas semanais), auxiliando nos processos administrativos da área.

Nos programas incorporados, como o PEP, foram contratados apenas profissionais graduados em educação física, sendo estes distribuídos de forma a ocupar cada setor, fato este associado aos controles de horas e produção, interferindo minimamente na produtividade das áreas (antes, apenas estagiários de educação física se encontravam presentes, e sem aplicabilidade à produtividade).

Na vigência do panorama descrito, foi possível coletar uma série de dados com base científica, apresentados no Congresso Brasileiro de Medicina do Esporte e Exercício no ano de 2015, com enfoque dos ganhos de flexibilidade e 
resistência muscular de uma amostra de funcionários da empresa foco deste relato.

Com relação ao PPCD, foram desenvolvidas pesquisas de acessibilidade individualizadas a cada um dos funcionários já incorporados ao quadro da empresa, sob a ótica da criação de oportunidades de melhoria no desenvolvimento de suas respectivas funções, assim como também foram realizadas incorporações ao programa de novos funcionários que foram identificados com base na análise de prontuários, compondo assim a cota de pessoas com necessidades especiais definida pelo Ministério do Trabalho. Passaram a ser monitoras as porcentagens de deficientes adequadas à companhia (antes estes eram apenas os funcionários de cota), ocorreram uma série de avanços com a criação de projetos de associação da Classificação Internacional de Doenças (CID-10) à Classificação Internacional de Funcionalidade (CIF), buscando melhorar a compreensão dos gestores quanto ao papel de cada funcionário, além de esclarecidas suas capacidades funcionais ao trabalho, e por fim, nas ações do PQVT, foram ampliados os controles, com encaminhamento dos casos alterados, guiando campanhas de prevenção e promoção de saúde durante todo o ano, conforme perfil epidemiológico da amostragem populacional da empresa, grau de risco ocupacional e Classificação Nacional de Atividades Econômicas (CNAE).

Foram criados escopos de tarefas para cada categoria profissional atuante na empresa, afim de que cada colaborador conhecesse suas atribuições principais, além de suas atividades correlatas aos demais. Nessa matriz de habilidades, o gerenciamento das atividades passou a ser mais eficaz e eficiente por parte do médico do trabalho, cuja missão era desenvolver e treinar cada um deles. Assim, no guia prático gestão ocupacional posterior, ficaram dispostas todas as funções e/ou atribuições destes funcionários, desde o coordenador da medicina do trabalho, até os auxiliares administrativos e estagiários.

Sob o aspecto organizacional, focou-se na valorização do capital humano(9), oferecendo suporte necessário para que essas pessoas desenvolvessem novas aptidões, com o aperfeiçoamento das características que já possuíam. Neste cenário, foram agregados elementos de uma organização com crescimento contínuo, onde todos contribuem para um ambiente de eficiência e eficácia. Assim, este capítulo teve como foco a gestão de pessoas na Coordenação de Medicina do Trabalho.

Quanto à gestão de serviços em saúde, esta focou nos níveis de competência da estrutura dos serviços (10), compreendendo o âmbito das ações básicas de cada profissional. Foram introduzidas algumas reflexões sobre 0 gerenciamento de natureza técnico-prática, operacionalizando a atenção primária, sempre na figura do gestor nas esferas de responsabilidade no âmbito empresarial. O trabalho visou, sempre, identificar as ferramentas que existiam, e como poderiam ser utilizadas para transpor as dificuldades diárias da gestão, como por exemplo, como entender, avaliar e planejar estratégias para as características locais. 
Obviamente, não foram esgotados todos os conteúdos e conceitos associados à temática, como a complexidade da gestão dos serviços de saúde (11). Porém, foram criados subsídios para discussão e reflexão sobre diversos temas, constituindo-se como passos importantes no entendimento do universo da empresa local.

Nesse sentido, o guia criado apresentou subcategorias relacionadas ao fluxo de atendimento, treinamento e controle de uso de recursos de materiais de consumo. Além disso, foi estabelecido como deveria ocorrer a assistência à saúde em atividades externas, além de tópicos que se referiam à odontologia ocupacional (12).

Com relação à gestão de insumos e suprimentos, deu-se foco à principal problemática do setor, o gerenciamento dos suprimentos em si. O setor apresentava variadas complicações, como a falta de materiais para as etapas seguintes de um atendimento clínico, falta de informações importantes para a elaboração de prescrição com assertividade em um serviço de saúde, dentre outras. Apesar de os suprimentos serem de grande importância para uma área, os insumos também possuem sua relevância, visto que o valor dos itens desperdiçados é de suma importância (13).

Foram construídas projeções financeiras para assegurar decisões estratégicas, analisando custos, despesas e investimentos para a determinação da margem de contribuição e o ponto de equilíbrio, sempre considerando os aspectos mercadológicos para cada situação. Passou-se a elaborar o planejamento orçamentário para a maximização de resultados, além de comparação de simulações financeiras para avaliar alternativas de mudanças estruturais na área de saúde, com o planejamento de estratégias empresariais (11).

Para fechar a estruturação operacional, foi trabalhada a Gestão de Métodos e Processos (7), sendo feito o planejamento e acompanhamento de sua execução, além de aperfeiçoamento contínuo, tornado o setor eficaz e efetivo. Para tal, levou-se em conta as necessidades e expectativas dos funcionários internos e externos. Durante o processo, foram identificados diversos problemas, quando então foram executadas as ações de melhoria correspondentes, aplicando-se às necessidades que os funcionários e a empresa apresentavam. Vale ressaltar que foi mantido o cuidado com as expectativas dos funcionários do Serviço.

$\mathrm{Na}$ avaliação dos aspectos relacionados aos métodos e processos, buscou-se identificar, entender e gerenciar os processos inter-relacionados como um sistema que contribui para a eficácia e eficiência da organização, no sentido de que esta possa atingir seus objetivos gerenciais. Foram identificados e implementados processos necessários para as operações da organização.

Ainda, foram estabelecidos os controles de entradas e saídas de cada processo, atribuindo responsabilidade e autoridade a cada funcionário envolvido na atividade.

\section{DISCUSSÃO}


Consoante à dinâmica empresarial do mundo globalizado, foi possível identificar que, mesmo que no Brasil, uma gestão centrada na missão, visão e valores de uma cultura francesa (14), na qual a companhia esteve inserida, e seguiu até o início do segundo semestre de 2015, quando então passou, no final de 2015, para uma cultura americana (15), que apresenta outra metodologia de trabalho, permitiu enriquecer ainda mais os aspectos da gestão, compartilhando todos os conhecimentos e agregando os pontos fortes de cada estrutura da organização.

Neste cenário de riqueza de informações, foi possível gerar novas práticas de gestão em saúde, proporcionando mais segurança e motivação na equipe, além de permitir a troca de experiências na interdisciplinaridade de profissionais (16). O setor de gestão de pessoas se desenvolveu com base na participação, na capacitação, no envolvimento, e no desenvolvimento dos profissionais da área de saúde da empresa foco do presente relato.

Nesse sentido, entende-se que os serviços de saúde precisam se manter atentos à variedade e quantidade de insumos utilizados em cada atendimento, que vão desde gazes à agulha. Neste passo, notou-se que os funcionários responsáveis por esses materiais nem sempre apresentavam preparo adequado e tempo para realizar o controle de forma eficiente. Todavia, situações como a descrita não deveriam impedir uma boa gestão de suprimentos, visto que existem estratégias para manter a referida área sempre sob controle, sem abrir mão da agilidade e da produtividade, tão necessárias ao serviço de saúde (17).

Com base no referido cenário, conhecer as demandas do serviço, além de consultar orçamentos e planejamentos de compras, se mostram como etapas fundamentais para manutenção dos estoques para que estes estejam preparados para atender às etapas de execução após cada atendimento, evitando assim compras em duplicidade, ou mesmo emergenciais, que devem sempre ser evitadas (18).

É preciso garantir condições de armazenamento ideais para cada tipo de material, assegurando que estejam sempre prontos para uso. O ideal é que os medicamentos mais sensíveis, não sejam muito manuseados enquanto estiverem estocados, pois correm o risco de cair e se quebrar. Deve-se manter sempre em estoque uma quantidade mínima de itens de consumo constante, como analgésicos simples e gazes. Realizar um inventário periodicamente, emitindo relatórios para conferência dos produtos disponíveis, e checar se os dados registrados estão de acordo com a realidade, também deve ser tarefa do gestor.

Uma solução tecnológica para integrar informações dos diversos produtos e áreas administrativas, assim como acesso a dados de consumo preciso em tempo real, são fatores primordiais para o sucesso de todo o processo, tornando a entrada e saída de itens mais ágil e assertiva (19).

Assim, ter controle da movimentação do consumo garante uma série de benefícios, como o cumprimento das datas de validade dos insumos, a redução de custos com compras mais assertivas, a disponibilização de produtos certos 
com agilidade para quem trabalha no local, além do fornecimento de dados corretos para eficiência na realização de orçamentos os mais próximos possíveis da realidade do setor. Uma gestão de suprimentos organizada ajuda a poupar o tempo de quem a realiza, seja no cadastro, localização ou movimentação de medicamentos (20).

Na gestão pela qualidade, foi elaborado um raciocínio com base nas categorias de qualidade. Dentre elas, destaca-se o fato de que promover segurança ao paciente, e auxiliar em decisões estratégicas, é indispensável. Na gestão da qualidade em saúde, pode-se planejar, organizar e desenvolver ações, avaliando os processos assistenciais, ocupacionais e gerenciais no serviço (21).

A qualidade de um produto ou serviço pode ser mensurada quando esta atende às necessidades de seus clientes de forma agradável (22). Além disso, cada pessoa tem uma visão diferente no momento de comprar um produto ou de desfrutar de um serviço, visto que estarão baseadas naquilo que aprenderam, nas suas expectativas, e em suas necessidades, que poderão ser distintas.

Neste campo, identificar, analisar e melhorar os processos que mais impactam na satisfação dos clientes se torna fundamental para alcance da qualidade (22). Dessa forma, foram elaborados planos táticos e operacionais em todos os diferentes níveis organizacionais. Foram analisados e interpretados os processos de melhoria que necessitavam de mudanças no comportamento, além da superação de barreiras departamentais.

Para tanto, foi trabalhado o desenvolvimento de serviços e ferramentas para diagnosticar situações necessárias à implementação de um sistema de qualidade e de auditorias internas, envolvendo produtos, serviços e pessoas (23). Pela gestão financeira, foram aprimorados ferramentas, instrumentos e processos, possibilitando a organização e o controle financeiro, com vistas à melhor gestão do capital atribuído ao departamento médico da empresa.

Diante de todos os aspectos qualitativos descritos, apontam-se alguns parâmetros quantitativos de base norteadora da gestão ocupacional, fornecendo ainda destaque para a necessidade de monitoramento contínuo do perfil epidemiológico dos colaboradores (Tabela 1). Entende-se que estes são os melhores indicadores de base para campanhas de prevenção e promoção de saúde, especialmente com relação aos casos de hipertensão, diabetes, obesidade, dentre outras comorbidades. Estes apontamentos, ligados à atenção primária, são capazes de reduzir a sinistralidade dos planos de saúde oferecidos pelas empresas.

Tabela 1. Métricas com base na amostra de 1116 funcionários da empresa avaliada.

\begin{tabular}{lll}
\hline GÊNERO & $N^{\circ}$ Absoluto & $\%$
\end{tabular}




\begin{tabular}{lrr} 
Masculino & $\mathbf{9 9 3}$ & $\mathbf{8 8 , 9 8}$ \\
Feminino & 123 & 11,02 \\
\hline FAIXA ETÁRIA & & \\
28 a 37 & 441 & $\mathbf{3 9 , 5 2}$ \\
38 a 47 & 315 & 28,23 \\
\hline ESCOLARIDADE & & \\
Ensino Médio Completo & $\mathbf{2 1 0}$ & $\mathbf{1 8 , 8 2}$ \\
Educação Superior & 108 & 9,68 \\
\hline ESTADO CIVIL & & \\
Casado & 597 & $\mathbf{5 3 , 4 9}$ \\
Solteiro & 433 & 38,8 \\
\hline FUNÇÃO & & \\
Fabril & $\mathbf{6 7 0}$ & $\mathbf{6 0 , 0 4}$ \\
Administrativa & 456 & 40,86 \\
\hline TURNO TRABALHO & & \\
$\mathbf{1}^{\circ}$ 7h15 às 17h36 & $\mathbf{7 9 5}$ & $\mathbf{7 1 , 2 4}$ \\
$2^{\circ}$ 17h30 às 03h07 & 152 & 13,62 \\
\hline
\end{tabular}

Ainda com base no monitoramento apresentado na Tabela 1, sugere-se seguir com os controles sistemáticos das frequências absoluta e relativa de acometimentos, em conformidade legal com os critérios estabelecidos pelas normas regulamentadoras do Ministério do Trabalho. Nesse sentido, destacase a classificação desses aspectos como GHE, estabelecidos por recursos humanos / gestores, segurança e saúde, respectivamente, o que permite a discussão dos tópicos associados à referida temática no tripé $\mathrm{RH}$, segurança $\mathrm{e}$ saúde.

Nessa estruturação, com base nas descrições relativas ao cargo/função de cada trabalhador, obtidas junto ao setor de recursos humanos com gestores, é possível definir os riscos químicos, físicos e biológicos aos quais os colaboradores estão expostos. Ainda, permite-se avançar para a identificação dos riscos ergonômicos e relacionados aos acidentes de trabalho, informações estas que devem estar disponíveis no setor de segurança do trabalho. Por fim, a área de saúde ocupacional deve determinar quais são os exames de saúde necessários para monitoramento da saúde dos colaboradores de cada setor, além de suas respectivas periodicidades. Apesar de importantes, entende-se que apenas esses indicadores não são suficientes para uma boa gestão de saúde ocupacional, sendo recomendada atenção para a criação de métricas que deverão servir como indicadores âncora, conforme os desdobramentos de cada negócio / empresa. Assim, nesta experiência compartilhada, exemplificase a métrica metodológica aplicada, demonstrada na Tabela 2.

Tabela 2. Métricas com base de estruturação de cada negócio.

\begin{tabular}{lll}
\hline Segurança Pessoas Qualidade & $\begin{array}{l}\text { Capacidade Financeiro } \\
\text { Resposta }\end{array}$
\end{tabular}




\begin{tabular}{|c|c|c|c|c|}
\hline $\begin{array}{l}\text { Acidentes de } \\
\text { trabalho sem dias } \\
\text { perdidos }\end{array}$ & $\begin{array}{l}\text { Taxa } \\
\text { Absenteísmo } \\
\text { com CID-10 } \\
\text { e área }\end{array}$ & $\begin{array}{l}\text { Atendimento } \\
\text { ao cliente } \\
\text { na área de } \\
\text { saúde }\end{array}$ & ASO emitido & $\begin{array}{l}\text { Reclassificações } \\
\text { de custos / setor }\end{array}$ \\
\hline $\begin{array}{l}\text { Acidentes de } \\
\text { trabalho com dias } \\
\text { perdidos }\end{array}$ & $\begin{array}{l}\text { Dias } \\
\text { perdidos - } \\
\text { menos } 15 \\
\text { dias }\end{array}$ & $\begin{array}{l}\text { Coaching } \\
\text { Bem-estar }\end{array}$ & PCA & $\begin{array}{l}\text { Kanban saúde } \\
\text { (controle } \\
\text { estoque) }\end{array}$ \\
\hline \multirow[t]{2}{*}{ Vacinas } & $\begin{array}{l}\text { Dias } \\
\text { perdidos - } \\
\text { mais de } 15 \\
\text { dias (B31 e } \\
\text { B91) }\end{array}$ & $\begin{array}{l}\text { Coaching } \\
\text { Nutrição }\end{array}$ & PPR & $\begin{array}{l}\text { Radar } \\
\text { depreciação de } \\
\text { bens }\end{array}$ \\
\hline & $\begin{array}{l}\text { Trabalhos } \\
\text { Adaptados } \\
\text { temporários }\end{array}$ & $\begin{array}{l}\text { Coaching } \\
\text { Atividade } \\
\text { Física }\end{array}$ & $\begin{array}{l}\text { GDOM e } \\
\text { PRT }\end{array}$ & $\begin{array}{l}\text { Revisão } \\
\text { contratos }\end{array}$ \\
\hline
\end{tabular}

Por intermédio dessas métricas (segurança, pessoas, qualidade, capacidade, resposta e financeiro), de forma hierárquica, coordenadores, gerentes e diretorias, podem acompanhar o desenvolvimento do capital humano da companhia. A seguir são apresentados os apontamentos mais críticos no olhar de cada uma das referidas métricas.

Pela métrica de segurança, com uma ampla visão de acidentes de trabalho sem dias perdidos, tornou-se possível discutir as ocorrências que, apesar de não gerarem afastamentos, apresentaram alguma interferência na cadeia produtiva. Os acidentes de trabalho com dias perdidos interferem no Fator Acidentário de Prevenção (FAP), que por sua vez afere o desempenho da empresa dentro da sua respectiva atividade econômica.

O FAP consiste em um multiplicador variável num intervalo contínuo de cinco décimos $(0,5000)$ a dois inteiros $(2,0000)$, aplicado com quatro casas decimais sobre a alíquota dos riscos ambientais do trabalho (RAT), que representa a contribuição da empresa em relação a este indicador. Trata-se de um percentual que mede o risco da atividade econômica, sobre a qual é cobrada uma contribuição para financiar os benefícios previdenciários decorrentes do grau de incidência de incapacidade laborativa, com alíquotas de contribuição de $1 \%$ se a atividade é de risco mínimo; $2 \%$ se de risco médio e de $3 \%$ se de risco grave. Essas taxas incidem sobre o total da remuneração paga, devida ou creditada a qualquer título, no decorrer do mês, aos segurados empregados e trabalhadores avulsos. Havendo exposição do trabalhador a agentes nocivos que permitam a concessão de aposentadoria especial, há acréscimo das alíquotas na forma da legislação em vigor. 
Quanto às taxas de absenteísmo relacionadas ao CID-10 e sua área, estas podem sensibilizar os gestores de forma que estes viabilizem a discussão junto ao setor de saúde laboral sobre formas de minimizar e/ou extinguir os afastamentos mais prevalentes. Nessa linha de raciocínio também é possível traçar junto ao setor de saúde estratégias para a formulação de campanhas visando reduzir os afastamentos por auxílio-doença (B31) e auxílio-acidente (B91), bem como viabilizar ações de correções ergonômicas pelos controles de atividades adaptadas temporárias.

Pela qualidade, o marcador de atendimento ao cliente na área de saúde apresenta uma visão de como são realizados os atendimentos aos funcionários, possibilitando que estes opinem em relação às mudanças que podem influenciar positivamente na qualidade do atendimento diário no referido setor. Também pela qualidade, é possível direcionar melhor os casos ao coaching de bem-estar, com foco nos aspectos de saúde mental, ou coaching de nutrição, que focará nas adequações e direcionamentos vinculados à importância de uma alimentação mais saudável, e até mesmo o coaching de atividade física, incentivando os funcionários à prática regular de exercícios, reduzindo o sedentarismo.

Pela capacidade resposta, é possível balizar as metas de quantos exames ocupacionais foram realizados a cada mês por meio das emissões de ASO, assim como nos aos programas de PCA, PPR, GDOM e demais.

Por fim, com base no financeiro, é possível adequar as programações de custos da área de saúde às demais áreas produtivas da companhia, calibrando projeções sempre atreladas ao orçamento, com melhor visibilidade do processo de depreciação, revisão de contratos e entrega de serviços.

Com base nas discussões apresentadas neste relato de experiência, cabe ressaltar que os trabalhos de saúde ocupacional refletem o que ocorre nas demais áreas da empresa, expressando em números onde cada gestor deverá interferir no sentido de cuidar para que sejam seguidos os preceitos relacionados à manutenção do estado de saúde dos colaboradores. $O$ monitoramento epidemiológico contínuo, atrelado a uma unidade de tempo (semanas, meses ou anos), facilita a tomada de decisão conforme sua necessidade naquele momento, contribuindo para que a empresa alcance seus objetivos estratégicos.

\section{CONCLUSÃO}

Este relato demonstrou que foi possível implementar ferramentas de gestão de saúde no serviço de saúde ocupacional da empresa estudada, agregando valor aos profissionais da equipe de saúde, agilidade nos processos internos, maior conforto aos clientes, e liberação dos usuários mais rapidamente para retorno aos seus respectivos setores de trabalho, certificando que os ajustes físicos e operacionais nas áreas de saúde das empresas surtem resultados positivos. Também, diante da condução dos processos descritos neste estudo, foi 
possível relatar a experiência vivenciada com as transformações na cultura da empresa, que acabou por refletir nas ações de gestão do seu serviço de saúde.

Como principais limitações, assume-se que este relato de experiência descreveu a implementação de um serviço de saúde ocupacional em apenas uma única empresa, e de um setor específico, que é o ramo de metalurgia, sendo ainda relativo a um período de seguimento de apenas dois anos. Dessa forma, novos estudos envolvendo um maior número de casos, com empresas de diferentes áreas, e com tempo de seguimento prolongado, poderão ser conduzidos para avaliar se os resultados apontados neste relato poderão se repetir quando avaliados em maior escala.

\section{REFERÊNCIAS}

1. Sancho LG, Dain S. Avaliação em Saúde e Avaliação Econômica em Saúde: introdução ao debate sobre seus pontos de interseção. Ciência Saúde Coletiva. 2012;17(3):765-774.

2. Rosenthal G. A estrutura e a gestão das autobiografias e suas consequências metodológicas. In: Usos e abusos da história oral. São Paulo: Editora FGV; 2015.

3. Cerqueira JP de. Sistemas Integrados de Gestão ISO 9001, ISO 14001, OHSAS 18001, SA 8000, NBR 16001 Conceitos e Aplicações. Rio de Janeiro: Qualitymark; 2006.

4. OHSAS. OHSAS 18001:2007. Occupational Health and Safety management systems. Requirements. 2007. Disponível em: https://www.bsigroup.com/enGB/ohsas-18001-occupational-health-and-safety/

5. NBR. NBR ISO 14001:1996 - Sistemas de gestão ambiental - Especificação e diretrizes para uso. [Internet]. 1996. Disponível em:

http://www.labogef.iesa.ufg.br/labogef/arquivos/downloads/NBRISO14001_5 9064.pdf

6. Palmisano A, Rosini AM. Administração de Sistemas de Informação e a Gestão do Conhecimento. São Paulo: Thomson; 2003. 234 p.

7. Pereira AM, Giuliani AC, Neto MS. Redesenho dos processos de negócio e aprendizagem organizacional: estudo em uma empresa de medicina ocupacional. REA-Rev Eletrônica Adm. 2014;13(1):120-134.

8. Lima FET, Jorge MSB, Moreira TMM. Hospital humanization: professional satisfaction in a pediatric hospital. Rev Bras Enferm. 2006;59(3):291-296.

9. Brás FA. Necessidade e dificuldades em valorizar o capital humano.

Tékhne-Rev Estud Politécnicos. 2007;(7):291-319. 
10. Brandão HP, Borges-Andrade JE, de Freitas IA, Vieira FT. Desenvolvimento e estrutura interna de uma escala de competências gerenciais. Psicol Teor E Pesqui. 2010;26(1):171.

11.Schraiber LB, Peduzzi M, Sala A, Nemes MIB, Castanhera ERL, Kon R. Planejamento, gestão e avaliação em saúde: identificando problemas. Ciência Saúde Coletiva. 1999;4(2):221-242.

12. Hiroishi WK, Rosetti E, Orenha ES, Naressi SCM. Odontologia do Trabalho: um novo olhar sobre a saúde bucal do trabalhador. Braz Dent Sci. 2012;14(3/4):66-76.

13. Silva SH da, Fernandes RÁQ, Gonçalves VLM. A administração de recursos materiais: importância do enfoque de custos e a responsabilidade dos profissionais de saúde. Rev Bras Enferm. 1994;47(2):160-164.

14. Scorsolini-Comin F. Missão, visão e valores como marcas do discurso nas organizações de trabalho. Psico. 2012;43(3).

15. Cavalcanti BS, Otero RB. Novos padrões gerenciais no setor público: medidas do governo americano orientadas para o desempenho e resultados. 1997 [citado 15 de maio de 2017]; Disponível em: http://bibliotecadigital.fgv.br/dspace/bitstream/handle/10438/12890/0000842 29_86.pdf?sequence $=1$

16. Pasqual KK, Braccialli LAD, Volponi M. Alojamento conjunto: espaço concreto de possibilidades e o papel da equipe multiprofissional. Cogitare Enferm. 2010;15(2).

17. Gomes D, Souza Ramos FR. Subjetividade, ética e produtividade em saúde pós-reestruturação produtiva. Rev Ciênc Saúde Coletiva. 2015;20(8).

18. Garcia E, Lacerda L, Arozo R. Gerenciando incertezas no planejamento logístico: o papel do estoque de segurança. Rev Tecnol. 2001; 63:36-42.

19. Paulus Jr A. Gerenciamento de recursos materiais em unidades de saúde. Rev Espaço Para Saúde. 2005;7(1):30-45.

20.Zucchi P, Del Nero C, Malik AM. Gastos em saúde: os fatores que agem na demanda e na oferta dos serviços de saúde. Saúde E Soc. 2000;9(12):127-150.

21. Ceccim RB, Feuerwerker LC. O quadrilátero da formação para a área da saúde: ensino, gestão, atenção e controle social. Physis. 2004;14(1):41-65.

22. Bittar OJN. Indicadores de qualidade e quantidade em saúde. Rev Adm Saúde. 2004;6(22):15-18.

23. D'Innocenzo M, Feldman LB, Fazenda NR dos R, Helito RAB, Ruthes RM. Indicadores, auditorias, certificações: ferramentas de qualidade para gestão em saúde. In: Indicadores, auditorias, certificações: ferramentas de qualidade para gestão em saúde. São Paulo: Martinari; 2010. 
Recebido: 07 de julho de 2018. Publicado: 20 de setembro de 2018

Correspondência: Renato Ribeiro Nogueira Ferraz. E-mail:

renatobio@hotmail.com

Conflito de Interesses: os autores declararam não haver conflito de interesses.

(C) This is an Open Access article distributed under the terms of the Creative Commons Attribution License, which permits unrestricted use, distribution, and reproduction in any medium, provided the original work is properly cited 